\title{
La vida nocturna: flujos y configuraciones semióticas, estéticas y metafopológicas*
}

\author{
Jorge Echavarría Carvajal \\ Universidad Nacional de Colombia, Medellín, Colombia \\ jechavar@unal.edu.co \\ https://orcid.org/0000-0001-9947-561X
}

\section{RESUMEN}

Más allá de su definición ligada a la rotación terrestre, la noche ha ofrecido un rico campo de producción simbólica, metafórica y estética a través del tiempo. Este artículo hace un recorrido desde los referentes míticos y folklóricos hasta las relaboraciones imaginarias y conceptuales derivadas, en un primer momento, de la filosofía moderna y el arte y, en un segundo momento, de los imperativos de la economía, la tecnología y el urbanismo. A partir de allí, el temor inspirado por las configuraciones atribuidas a lo nocturno van cediendo paso a la conquista y domesticación de esta dimensión espaciotemporal: mercantilización, turismo y polución lumínica marcan hoy las coordenadas de una posible desaparición de esta fuente simbólica. Ahora bien, estas coordenadas presentan rasgos muy diversos en distintas culturas y la aparición de nuevas formas y figuras encarnan miedos contemporáneos o residuales del pasado desplegados en los contenidos del cine y los medios. Por otro lado, se compara la nocturnidad de Medellín con el de otras experiencias y se propone un norte diferente para su gestión, más acorde con las dinámicas reales que suceden en este espacio cronológicamente definido.

Palabras clave: semiótica; estética; metaforología; mitos; imaginarios; noche; mercantilización; contaminación lumínica; ciudades; miedo.

* Cómo citar: Echavarría Carvajal, J. I. (2019). La vida nocturna: flujos y configuraciones semióticas, estéticas y metaforológicas. Ciencias Sociales y Educación, 8(15), 23-39. DOI: https://doi.org/10.22395/csye.v8n15a2 Recibido: 6 de noviembre de 2018.

Aprobado: 7 de marzo de 2019. 


\section{Nightlife: Fluxes and Semiotic, Aesthetic and Metaphorogical Configurations}

\section{ABSTRACT}

Beyond its definition linked to the rotation of the earth, night has offered a rich field of symbolic, metaphoric and aesthetics production throughout time. This article goes over the mythical and folkloric references up to the derived imaginative and conceptual reworkings. First from modern philosophy and art and then from economic imperatives, technologies and urbanism. From there, the fear inspired by the settings attributed to the nocturnal starts to yield to the conquest and domestication of this space-time dimension: commodification, tourism and night pollution gives now the coordinates for a probable disappearance of this symbolic source. Now, these coordinates present diverse characteristics in different cultures and the appearance of the new forms and figures incarnate the contemporary fears or those residual from the past and deployed in the contents of movies and media. Moreover, if the nightness of Medellín is compared with other experiences and a new north for its management is proposed more accordingly with the real dynamics of this space chronologically defined.

Keywords: semiotic; aesthetic; metaphorology; myths; imaginaries; night; commoditization; light pollution; cities; fear.

\section{A vida noturna: fluxos e configurações semióticas, estéticas e metafóricas}

\section{RESUMO}

Mais além de sua definição ligada à rotação terrestre, a noite oferece um rico campo de produção simbólica, metafórica e estética através do tempo. Este artigo faz um percorrido desde os referenciais míticos e folclóricos até as reelaborações imaginárias e conceituais derivadas, em um primeiro momento, da filosofia moderna e da arte, e, em um segundo momento, dos imperativos da economia, da tecnologia e do urbanismo. A partir disso, o temor inspirado pelas configurações atribuídas ao noturno vai dando lugar à conquista e domesticação dessa dimensão espaço-temporal: mercantilização, turismo e poluição luminosa marcam hoje as coordenadas de um possível desaparecimento dessa fonte simbólica. Essas coordenadas apresentam traços diversos nas culturas, e o surgimento de novas formas e figuras trazem medos contemporâneos ou residuais do passado registrados no cinema e nos demais meios de comunicação. Por outro lado, compara-se a noturnidade de Medellín, Colômbia, com a de outras experiências e propõe-se um caminho diferente para sua gestão, que esteja mais coerente com as dinâmicas reais que acontecem nesse espaço cronologicamente definido.

Palavras-chave: semiótica; estética; metaforologia; mitos; imaginários; noite; mercantilização; poluição luminosa; cidades; medo. 


\section{Introducción}

La actividad nocturna, potenciada por las prácticas e imaginarios del fin de semana y del ocio, aparece hoy figurada como recompensa que se abre como oasis frente a la semana laboral. Lo nocturno ha sufrido, en los últimos tiempos, transformaciones significativas. De hecho, el jueves, redenominado juernes ${ }^{1}$ en el slang urbano para crear una filiación y continuidad con el viernes, se incorpora a este "paquete" de actividad de fin de semana. En este sentido, se captura el interés de diversos noctámbulos a través de estrategias, tales como promociones realizadas por los sitios de fiesta: juernes de contrabando en los que se permite la entrada de licor al establecimiento sin ninguna penalización, happy hour, compra de dos bebidas y entrega de tres, noche de mujeres, etc. También se programan encuentros deportivos prolongados con rumba celebratoria tras el fin del evento, sin que importe el resultado del encuentro.

Durante 80 minutos el jueves fue un juernes de verdad, de los que gustan a los barranquilleros, de esos que convierten el fin de semana en eternos, de los que hacen que el viernes parezca domingo, ideal para mantener el mismo tema de conversación durante todos los días que haga falta. Fueron ochenta minutos en los que Junior primero dominó el partido en el juego y en el marcador, y luego cedió ante la presión del Flamengo para acabar perdiendo por la mínima. (Escorcia, 2017)

Los universitarios repiten la ancestral costumbre goliardesca que heredan del mundo medieval, y la apropiación de espacios de encuentro aledaños a los campus desde este día o los días de semana previos a un festivo o a un receso vacacional $^{2}$. En campañas diseñadas por entidades de turismo ${ }^{3}$; las tecnologías de comunicación y sus redes sociales estimulan la autopromoción, el consumo y la ostentación para compartir momentos minuto a minuto a través del registro fotográfico.

1 El neologismo se ha generalizado en el ámbito hispanoparlante y se encuentra en muchos países. En México, también se denomina “juebebes", ligando semánticamente el nombre del día con la actividad de consumo de licor.

2 En España, los bares convocan a eventos como los “Jueves subterráneos', 'Jueves acústicos', 'Juevintxo' o 'Juernes slow'. En este país, muchos estudiantes no tienen clases programadas para el viernes.

3 "Los 'juernes' cada vez ganan más adeptos en Madrid. Salir un jueves por la noche como si fuera un viernes o un sábado es algo que cada vez prueba y disfruta un mayor número de madrileños, en concreto 10.000 más que hace solo unos meses. Éste es el balance que este jueves ha hecho la Plataforma de Asociaciones por el Turismo, el Ocio, la Hostelería y la Cultura de la Comunidad de Madrid de la segunda campaña «Vuelven los jueves de Madrid», que se ha desarrollado durante los cinco primeros jueves del otoño coincidiendo con la nueva temporada de invierno, con más de setenta bares, restaurantes y otros comercios de ocio adheridos. (...) Para demostrarlo, han aportado algunos datos recabados a partir de encuestas: el $66 \%$ de los que respondieron dicen salir mucho o bastante los jueves frente al 53,1 \% de la primera campaña, lo que supone un incremento del $24 \%$, equivalente a 10.000 personas." (ABC, 2014) 
La cronología y topografía nocturnas se expanden y logran convocar el ansia del relax y de la diversión. Pero más allá de eso, configuran una experiencia humana básica: el uso semiótico de diversos instrumentos y registros para transmitir, recibir y negociar diferentes significados, como la elección de vestuario y accesorios, maquillaje, marcas selectas, moda, prendas básicas y sin pretensiones. En los sitios de consumo se configuran escenografías con tipos de música, grupos en vivo, necesidad o no de reservas o filtros de admisión, arquitectura, mobiliario y bebidas que implican ciertos "estilos" y atraen a sus seguidores, que se entretejen de modo "natural" en estas telarañas semióticas donde se practican rituales identitarios y de cortejo, indistinguibles hasta cierto punto. Según el concepto "metaformas" de Danesi (2013), los rituales, las expresiones y los artefactos se conectan semióticamente, constituyendo sistemas conectivos de sentido, intertextualidades atrapadas en tejidos de sistemas de referencias que caracterizan una cultura.

Más que un mero despliegue de astucia comercial para aprovechar y extender las noches de juerga, nos enfrentamos a modelos de resignificación cultural con un anclaje en nuestro ser histórico más arcano.

\section{Cosmologías y estéticas de la luz y la oscuridad}

Platón (1872), en el Timeo, pensaba que las estrellas eran "la forma móvil de la eternidad" (p. 23), expresando en este oxímoron su pretendida perennidad y sus contradictorias mudanzas, su regularidad y sus destellos, despertando lo que Fideler (2000) llama el "impulso cosmológico", es decir, el deseo, nacido del maravillarse ante el cosmos, de obtener una visión integrada del mismo y de nuestro lugar en tal totalidad. Este impulso da origen a la filosofía, a la cosmología, a la ciencia en la persecución de tal propósito común. En este sentido, afirma Platón (1872) en el Timeo:

La maravillosa utilidad de la vista, a mi parecer, es, que jamás hubiéramos podido discurrir, como lo hacemos, acerca del cielo y del universo, si no hubiéramos estado en posición de contemplar el Sol y los astros, La observación del día y de la noche, las revoluciones de los meses y de los años nos han suministrado el número, revelado el tiempo, e inspirado el deseo de conocer la naturaleza y el mundo. Así ha nacido la filosofía, el más precioso de los presentes que los dioses han hecho y pueden hacer a la raza mortal. (p. 191)

Platón va tras las huellas de su maestro Pitágoras al establecer la conexión entre las estrellas, la música y el número, tres facetas de la armonía universal, tres formas de hablar el lenguaje que gobierna tales aspectos: pulsos, ritmos, patrones y regularidades.

4 Todas las traducciones de términos y frases en otros idiomas son propias. 
No de modo accidental surge primero el vínculo con lo divino y luego con la racionalidad, la conciencia y las metaforologías de lo lumínico: plenitud de unidad, belleza y conocimiento, de reflejo de la inteligencia demiúrgica, tal como se despliega en el Mito de la caverna, o en el conciso y, por ello, aplastante, Fiat lux veterotestamentario (1 Gén.1:13). Esta metáfora y las semióticas lumínicas asociadas atraviesan el pensamiento occidental, tanto en sus corrientes dominantes como en muchas derivas marginales. En la Grecia clásica y la teología cristiana en su digestión del pensamiento platónico tiene su deriva estética en el seno de la escolástica, donde lo bello es esplendor. Está tras la catedral gótica y sus vitrales, el icono bizantino y el uso del oro como fondo de las imágenes sacras, como presencia-reflejo de la luz divina. Esta idea no fue asumida directamente de Platón, sino de Aristóteles y del neoplatonismo por medio de los árabes. Después, la metáfora lumínica fue recogida por la alquimia. Como lo refiere Martin (2011), el rey sol, oro, verdad, es capacidad de renovación, pero, renovado como "sol de los filósofos", transparente y opaco al tiempo, paradoja de luz y sombra. En la masonería esta metáfora tuvo que ver con el orden como luz contra la oscuridad caótica. También fue asumida por los esenios, la cábala judaica y el neoplatonismo. Plotino hablaba de la idea del sol como la belleza ideal, del Pseudo-Dionisio y la identidad entre luz y bien y de la participación en lo divino que se hace inteligible en lo lumínico. Pero también se han hecho intentos por establecer un carácter científico de la luz, esto es, el carácter matemático, correlato de la luz metafísica, del franciscano Robert Grosseteste. Por otro lado, se habla de la luz homogénea, plena y cenital renacentista frente al efectismo lumínico del barroco y su claroscuro. En el movimiento ilustrado se habló de Lumières, en francés; Enlightenment, en inglés; Illuminismo, en italiano; Aufklärung, en alemán: la ambigüedad romántica frente a la luz y la oscuridad. Por último, en algunas corrientes de arte contemporáneo se habla de luminismo tecnológico.

El otro gran cuerpo celeste en el cielo terrestre, la luna, sin luz propia y variable formalmente a lo largo de cada mes, precisamente se hace equivalente semiótica y metaforológicamente a lo inconstante, a una belleza que oculta una cara temible o amenazante, un influjo que cubre los ciclos del cuerpo fértil femenino, las mareas, los ciclos agrícolas, los ensueños y las pesadillas, los arrebatos maníacos, la inspiración, la muerte, la metamorfosis de los hombresbestias, los cuernos de la luna creciente plenos de una simbología ambigua y que están presentes en tradiciones tan viejas como las babilónicas, griegas, romanas y finalmente, cristianas.

Las asociaciones negativas con la oscuridad tienen una fecha de nacimiento inmemorial, pero están recogidas más recientemente, como es el caso de Platón, donde las sombras son interpretadas como proyección irreal y engañosa, 
como presencia elusiva de un objeto original. La historia que recoge Plinio el Viejo (2007) ubica el origen de la pintura en el juego de luz y sombra. Una joven delinea sobre el muro el contorno de la sombra de su amado presto a partir para conservar de él esa huella precaria. En este sentido afirma: "De los griegos, por otra parte, unos dicen que se descubrió en Sición, otros en Corinto, pero todos reconocen que consistía en circunscribir con líneas el contorno de la sombra de un hombre" (Plinio, 2007, p. 78 ). Dante, infructuosamente, trata de abrazar una sombra (Dante, 2019, Purg. II, 79-81). Los pintores usan esa zona indecible, más allá de la luz y la representación nítida, para sugerir algo que no se muestra pero que está ahí significando: el claroscuro chiaroscuro de Caravaggio, el sfumato de Leonardo o el tenebroso de Rembrandt (Stoichita, 1999). El tránsito espiritual de la oscuridad confusa y amenazante a la luz plena de los místicos dará entrada a la noche bohemia, carnal, pecaminosa y apasionada.

Los fenómenos estacionales o naturales, geográficos o meteorológicos, ligados a luces y sombras, despliegan otras formas simbólicas, semióticas y metaforológicas de manifestación y valoración de luz y oscuridad, de su mezcla o predominio de uno sobre otro, de incertidumbre, de estimaciones ambiguas a través de representaciones culturales de enorme fuerza: los eclipses, los cometas, las auroras boreales, el arco iris, los reflejos, las figuras en las nubes, las emanaciones, los gases luminosos, las oscuridades venidas de neblinas, los humos de erupciones volcánicas, los vientos que aclaran u oscurecen la atmósfera, las lluvias, los monzones, los ciclones, los huracanes, las tormentas, los relámpagos, la nieve cegadora, los fuegos, las chispas, las centellas, el crepúsculo, el alba, las constelaciones, los astros, los solsticios, las cavernas oscuras, las cumbres luminosas, los valles umbríos, las sabanas soleadas, las costas oscuras o iluminadas, los desiertos abrasadores o congelados, los bosques, las selvas llenos de exóticas criaturas y de soledad los pantanos, las marismas, las playas, las islas.

Los mitos y creencias populares concretan las asociaciones semióticas de lo monstruoso, lo temible y lo inconmensurable de su inhumanidad con las tinieblas, sombras y penumbras. Los diversos relatos folklóricos, recogidos en los proyectos decimonónicos de los $\mathrm{Grimm}^{5}$, expresan patentemente esas asociaciones entre los seres nocturnos, crepusculares y sombríos y sus habitáculos campestres: bosques, montañas y cuevas. Estas criaturas se esconden en las esquinas tenebrosas de las ciudades premodernas, que, al carecer de iluminación nocturna, favorecen esta mudanza subrepticia de lo agreste a las ciudades.

Cada momento de una cultura, acorde con sus relaciones y visiones del cosmos ancestrales o modernas, así como con la aparición, apropiación, valo-

Jacob y Wilhem Grimm fueron filólogos, investigadores culturales, lexicógrafos y escritores alemanes. Recogieron y popularizaron leyendas tradicionales como las de Cenicienta, Rapunzel, Blancanieves, La bella durmiente, Hansel y Gretel, canonizadas luego como piezas paradigmáticas de la llamada literatura infantil. 
ración y prevalencia de nuevos dispositivos sociales y técnicos, produce una panoplia de representaciones que se relevan, persisten o cambian de signo. Cada civilización produce sus propios sistemas semióticos para dar sentido a la luz y a la oscuridad, para explicar su alternancia, sea desde dispositivos míticos, estéticos o científicos. Así, Alain Corbin (1993), el historiador francés de las escuela de Annales, muestra cómo en el siglo XV europeo, el mar era mirado como depósito de atrocidades y sobrantes de la creación, como un territorio teratológico, oscuro y caótico que hacía la relación con él fuera de temor, a pesar de los descubrimientos geográficos de la época: "más que el límite de la tierra, las costas fueron durante siglos la prolongación última del mar" (p. 46). De esta manera, las costas y las playas eran fronteras minada de peligros, bordes frente a un abismo incomprensible, residuo enorme del diluvio y de la creación previa. Por ello, la contemplación del mar, incluso embravecido, se vería luego como una experiencia estética singular, que incluso desarrolla su propia categoría, la de lo sublime ${ }^{6}$. Al tiempo, al aminorar el prejuicio previo por lo otro y al aparecer el gusto por lo exótico junto con lo sublime que el mar comparte con montañas, aludes, cumbres, simas, ruinas, bosques, explosiones volcánicas, cataratas, hielos eternos ${ }^{7}$, etc., se desarrolla el gusto por lo bello de las costas lejanas, de los trópicos. Es el espejismo que perseguiría Gauguin, tal vez ya tardíamente. Como el mar, la noche y la oscuridad se verán adscritas a valoraciones y semióticas cambiantes, así como los de sus correlatos: sueño, caos, sombra, pesadilla, cromatismos apagados y sombríos, fauna amenazante, luna, fuerzas malignas, entre otros, de una forma que incluso nos podría hoy parecer extrema, tal como lo relata el historiador del color Michel Pastoureau (2017):

En la época feudal, por ejemplo, el Diablo y los demonios van acompañados de todo un cortejo de animales de pelaje o plumaje oscuro que parecen haber salido también del abismo infernal. Son, por una parte, monstruos o criaturas híbridas, pero también animales de verdad, como el oso, el lobo, la lechuza, los cuervos, el macho cabrío o el gato. Este último no es todavía el animal familiar que conocemos. Según los bestiarios, es un ser astuto y misterioso, traicionero e imprevisible, merodea alrededor de la casa o del monasterio, vive por la noche y asusta a las buenas personas, especialmente cuando luce piel negra. Es una criatura del Maligno y, como a este último, la señal de la cruz lo ahuyenta. Para espantar a ratas y ratones, se prefiere a la comadreja, más o menos domesticada desde la época romana. (pp. 160-161)

La oscuridad, productora de ansiedad y miedo, hunde sus raíces en nuestros orígenes más arcaicos y amenaza con destronar al mismo señor del relámpago luminoso, a Zeus. Nix, la deidad griega de la noche, también denominada Nicte,

6 Esta categoría fue rescatada por el retórico Longino a partir del siglo XVI en Italia, y de forma más cercana, por Nicolas Boileau-Despréaux y luego por Anthony Ashley Cooper, tercer conde de Shaftesbury, Joseph Addison y Edmund Burke, fuentes del modelo estético kantiano donde adquiere su sentido y peso más específico.

7 No sobra recordar que a estas heladas lejanías fue trasladado el monstruo hecho de retazos de cadáveres fabricado por el prometeico Frankenstein de Mary Shelley. 
es llamada por Hesíodo (1978) "bienaventurada y fuente de dioses y de hombres" (p. 78), en una clara afirmación de su complejo carácter ni maniqueo ni negativo. Es la hija de Caos y hermana de Érebo, Oscuridad. Con este último concibió a Éter, Luminosidad y a Hémera, Día. Luego, tiene por sí misma a Moros, Destino; Ker, Perdición; Tánatos, Muerte; Hipnos, Sueño; Geras, Vejez; Ezis, Dolor; Apate, Engaño; Némesis, Castigo merecido; Eris, Discordia; Filotes, Amistad o Ternura; Momo, Burla; las Hespérides, Hijas de la Tarde; los Oniros, los Sueños; las Keres, Espíritus de la destrucción y muerte; y las Moiras, Destino (Hard, 2004). Como se ve, es una extraña banda en la que se alinean los que para nosotros serían contrarios, por ejemplo Érebo y Éter, pero que conviven a la sombra de su poderosa progenitora. Esta lucha tiene su correspondencia en nuestra mitología judeocristiana encarnada en la dupla antagónica entre el Todopoderoso y Lucifer y sus asimilaciones entre la lucha maniquea entre bien y mal. Por otro lado, las mitologías egipcia, hindú y nórdica tendrán sendas versiones con asociaciones a eclipses, la muerte, el mal, etc. Tal vez la mitología donde se despliega una mayor complejidad de lo nocturno es en la azteca, donde 9 dioses, Yoalteuctin, presiden diferentes tipologías de lo nocturno, lo que también se da en la maya, pero no en la Tolteca que es dualista. Las atribuciones de estas divinidades son complejas. Abarcan la lluvia, los jaguares, el agua, la oscuridad, el fuego, los muertos, el maíz, etc.

Tras la dominación de estas figuraciones y despliegues semióticos durante toda la era premoderna, la aparición del proceso fabril, el auge de las vías férreas y de las vacaciones de los obreros, creará una curiosa conjunción con otros elementos que cambiaron dramáticamente las metáforas asociadas a costas, mares y playas. Se une a la fiesta una costumbre médica victoriana que receta baños de mar para presuntamente curar un sinfín de enfermedades: problemas de fertilidad, menstruales o de impotencia; problemas mentales y de ánimo, como la histeria y la melancolía; enfermedades infecciosas, como la lepra, y la tuberculosis; o de otra índole, como el asma, el raquitismo y la gota. Esto implicó una reorientación médico-hidrológica que fue cediendo lugar a la playa y fue haciendo pasar a un segundo plano los baños termales con sus sitios emblemáticos, tales como Marienbad, Vichy, Bath, entre otros, así como de la geografía de estos balnearios, situados en lugares montañosos y de bosques. Los tratamientos marinos de agua, sol, salinidad, paisajes, brisa comienzan a ser usados por los aristócratas, pero se democratizan pronto. Empiezan a aparecer, entonces, hoteles, trajes de playa, facilidades para su uso los cuales hoy nos parecen absolutamente "normales" e intemporales. De hecho, en la cantábrica Santander se celebra alrededor del 17 de julio una fiesta donde los bañistas usan trajes decimonónicos para conmemorar el día en el que la reina Victoria Eugenia, (esposa del rey Alfonso XIII y la bisabuela del actual rey español), se sumergió por primera vez en las aguas costeras, con lo que se popularizaron 
estas inmersiones y se convirtió en una práctica habitual de la alta burguesía. Frente a la polución urbana, la revalorización de las costas, otrora de valoración semiótica adversa, representaba una salida hacia las frías aguas atlánticas. Primero se dirigían hacia locaciones cercanas a las ciudades, pero luego con los ferrocarriles se empezaron a encaminar hacia costas más alejadas de los centros de población. Muchas veces, por el fenómeno de la imitación, los ciudadanos del común copiaron los usos de las clases altas y comenzaron a ocupar sus espacios de recreo que antes eran exclusivos. Este es el caso de Inglaterra, donde los miembros de la familia real visitaban Weymouth desde 1758, lo mismo que a su competidora Brighton, seguidos luego por una multitud menos exclusiva que fue configurando el turismo de masas en busca de los recién inventados placeres de la playa.

Asimismo, en una lógica parecida a la de la nueva valoración y cambio de signo de la espacialidad, la noche fue variando semiótica y metaforólogicamente. El prolífico Nicolas-Edme Restif de la Bretonne (2009) fue el cronista de las noches parisinas alrededor de la Revolución de 1789. En medio de la convulsa lucha política aparece un insospechado continente antes incógnito y temido: la noche ya transitable gracias a la cada vez menos precaria iluminación de las vías públicas. Con el reinado del rey $\mathrm{Sol}^{8}$, Luis XIV había iniciado esta conquista al instalar en París faroles alimentados con grasa vacuna o de cordero que espantaban, en parte, las sombras y los miedos a ellas asociados. Según Petrusich (2016), para 1890, más de 175.000 luminarias eléctricas habían sido instaladas en las calles de Estados Unidos; hoy, hay cerca de 26 millones, que le cuestan a los ciudadanos que pagan impuestos unos 6 billones en costos anuales de consumo energético. La porción otrora consagrada al miedo y al sueño inquieto, asechada por criaturas y seres malignos, abre una puerta a una ciudad donde habitan nuevas figuras, como el bohemio, el dandy el flâneur, el decadentista, la cocotte, el advenedizo rastacueros, las demimondaines o el hombre la de la multitud de Poe y Baudelaire. Asimismo, emergen nuevos lugares, como el café, el teatro, el cabaret, el prostíbulo, el boulevard. Allí seguirán asechando espectros de la ciudad abisal, monstruos como Jack el Destripador, entre otros. Pero ahora serán perseguidos, enfrentados policialmente y no meramente rehuidos. La literatura hizo de estos personajes y escenarios un festín: Balzac, Sue, Zola, Flaubert, Víctor Hugo, Dumas, Dickens, Verlaine. Pero también la ópera, el teatro, la pintura, el folletín, los carteles publicitarios hizo de estos su material de primera con artistas como de Toulouse Lautrec, Henry Murger ${ }^{9}$, Puccini, Wilde, Audrey Beardsley, entre otros. De hecho, nuestras tardías bohemias latinoamericanas se

8 Fue la asociación lumínica de larga carrera que el rey francés hizo propia, pero que encontramos luego en los afiches propagandísticos de la China Maoísta, donde el líder aparece nimbado de rayos luminosos y el pueblo, transformado en girasoles, sigue su fulgurante camino.

9 Henry Murger le dio nombre al fenómeno "Escenas de la vida bohemia" (1851) 
conectan con ese mismo flujo: Rubén Darío, Miguel Cané, Manuel Gálvez, Silva, los Panidas, Barba Jacob, etc. Ellos reclamaron su porción de bohemia nocturna contestataria y no ajustada al dominantemente diurno orden social burgués.

Deidades lumínicas o sombrías combatieron, y lo siguen haciendo en otras arenas, en mitos e imaginarios. Cada uno trata de imponer su dominio, sus ritmos y calendarios, sus rituales de obediencia, castigo o expiación. Los solsticios, del latín solstitium, sol sistere, sol quieto, son el eterno presente donde se renueva el ciclo vital. Las fases lunares que aconsejan o no la siembra, el corte de la madera o del pelo, son puntos de inflexión donde nacen los dioses ${ }^{10}$. Así, en el declive o en el esplendor solar o lunar, se marcan fechas donde lo divino y lo humano se aproximan o alejan al ritmo de calendarios que fijan rituales y acciones propiciatorias. Más que dividir o representar el tiempo, aluden al problema de la duración de lo humano y lo divino, como anota Carbonell (2004). Y lo mismo vale para todos los fenómenos lumínicos o de oscuridad, sean eclipses o constelaciones, auroras boreales o arco iris, crepúsculos o amaneceres, desde donde fotofilias y fotofobias desencadenan sus poderes semióticos y metaforológicos. Sin embargo, hoy estamos muy lejos de la luminosidad solar teológica y epistémica y mucho más cerca de un sol recreativo e intrascendente o tecnológicamente aprovechable a través de dispositivos de captación y almacenamiento de energía solar, vista hoy como una de las que componen el menú energético ecológicamente correcto del futuro inmediato (Bruzzi y Church, 2013).

\section{A la conquista de la noche}

Tampoco la noche, en ese proceso de conquista y dominio iniciado al calor de la revolución francesa y sus luces materiales e intelectuales, ha salido indemne: han variado significativamente sus referentes semióticos y las figuras metaforológicas que la encarnan. Las luces nocturnas de faroles y avisos, unidas hoy a cámaras y a circuitos de vigilancia, crean la sensación de control y seguridad plenos. Esta sensación se apareja con la virtual desaparición de la oscuridad, desterrada por la contaminación lumínica. Esta, omnipresente en cualquier ciudad o espacio poblado moderno, ya hace imposible experimentar la noche en el 80 \% de Europa y Norteamérica. De este modo, como relata Petrusich (2016), en 1994, tras un corte eléctrico al anochecer debido a un terremoto en la mayor parte de Los Ángeles, El Observatorio Griffith recibió llamadas telefónicas de

10 Tras celebrarse en diferentes fechas, el cristianismo terminó por situar en el año 354 el nacimiento de Cristo el 25 de diciembre, fecha del solsticio de invierno, en la que también se sitúa el nacimiento de Mitra, la divinidad más coincidente con Cristo. Según el Zend Avesta: "Ascendió a los cielos, donde mora; a su llamada, los muertos se alzarán en la tierra en donde se hallan sepultos y serán juzgados. Aquellos que durante su vida intentaron hacer el bien y vivieron para ello, subirán al Reino de los Cielos, pero los malignos y perversos, descenderán a las Tinieblas". Pero también es la fecha donde se ubican los nacimientos de Adonis para los asirios; de Tammuz, en Babilonia; del niño Horus egipcio; del Dioniso griego; del nórdico Freyr, hijo de Odín y Friga, dios de la luz; de las celebraciones con hogueras de San Juan, etc. 
asustados residentes preguntando por el "extraño cielo". Lo que esas personas estaban viendo eran las estrellas. El profesor Paul Bogard (2014), de la Universidad James Madison, utiliza una escala desarrollada por el astrónomo aficionado John E. Borttle, la cual mide el brillo del cielo nocturno, y que va de 1 (oscuridad perfecta) a 9 (centro de una ciudad). Así, el derecho a un cielo no polucionado lumínicamente ha hecho emerger defensores que claman por restituir esta experiencia evocada en el Timeo para la mayoría de los humanos. Evidentemente, esta difusa luminosidad omnipresente no solo tiene efectos estéticos, sino que afecta la vida de las plantas y los animales, tanto en ambientes salvajes como urbanizados. Adaptados bilógicamente a la alternancia de ciclos lumínico y de oscuridad, se han roto equilibrios precarios que se afectan con la iluminación artificial permanente: mientras que la actividad biológica animal es muy reducida a plena luz, durante la noche es abundantísima. De este modo se alteran los patrones de alimentación, orientación, reposo, reproducción, polinización, migración, defensa de predadores, etc., de aves, mamíferos e insectos. Esto también es palpable en los humanos con los efectos sobre las crecientes tasas de insomnio, estrés, descanso limitado, disfunciones sociales, etc. ${ }^{11}$

Imponderables son, por supuesto, además de estas consecuencias sobre la biosfera, los efectos que la desaparición de la noche tiene sobre la imaginación. La noche era, antes de la revolución industrial, y como bien lo vieron los románticos, una fuente de inspiración, una trinchera contra lo convencional e institucionalizado, una disonancia que introducía otras formas de ver y pensar diversas a las del rebaño adoctrinado y trabajador, en tanto que no se pedía a tal imaginación estar atada a ningún convencionalismo ni compromiso. De esta manera, la influencia de la poesía romántica y su valoración del dominio de lo tenebroso fue muy fuerte en la filosofía que vino después, como es el caso de Friedrich Von Hardenberg (Novalis). En este camino siguieron movimientos como el surrealismo o el Dadá, donde la experimentación onírica, el azar, la contravención del caudal de lo rutinario, se convirtieron en herramientas de creación cultural.

Las ciudades contemporáneas, iluminadas y activas durante todo el tiempo, no pueden, sin embargo, desterrar del todo las sombras y los espectros nocturnos que reaparecen a caballo de las crisis sociales y económicas urbanas. Para utilizarlo, el Comercio (2018), diario peruano, informa que

Al ocultarse el sol, la soledad reina en las calles de Caracas, castigada por la desbocada criminalidad y la crisis económica en Venezuela. Otrora llena de luz y movimiento y meca de ritmos caribeños como la salsa, la noche caraqueña se apaga. [...] Por la noche, muy pocos entran a las estaciones del Metro de Caracas,

1 Ver el listado de clasificación mundial de países en términos de su área, población y contaminación lumínica en Science Advances: https://advances.sciencemag.org/content/2/6/e1600377 
que moviliza a dos millones de personas diariamente. Cada jornada, el subterráneo cierra sus puertas a las 11:00. Puestos callejeros de hot dogs y hamburguesas esperan por clientes, sin éxito, en varias zonas. Los 'perreros' de Plaza Venezuela -simbólica locación en la ciudad- extrañan los días en los que no se daban abasto para atender comensales. No es diferente en el este. Las Mercedes, exclusiva y bulliciosa zona de restaurantes y locales nocturnos que hace unos años concentraba a quienes tenían ganas de fiesta, languidece. Ahora, los venezolanos prefieren hacer sus reuniones sociales en casa, de modo más seguro y más barato. (p. 18a)

Las "zonas rosas", espacios urbanos diseñados casi exclusivamente para la nocturnidad iluminada, entran en crisis y son abandonadas: terremotos, bandas criminales, monstruos reales o imaginados, desapariciones, delitos menores o mayores, reformas urbanas, mendicidad desbocada o simples rumores expandidos exponencialmente vía redes sociales, impactan, a veces de muerte, estos espacios. Por otro lado, el afán de novedad, la moda ligada a los espacios de consumo nocturno, desplazan funciones y deseos a otros lugares dejando maltrechas las viejas zonas rosa que se resisten a desaparecer ${ }^{12}$, dejando vagar a esas presencias renacidas desde los miedos más antiguos.

¿Termina la noche su andadura como fuente de símbolos acosada por la mercantilización de su temporalidad y el destierro de sus sombras por vía de las luces que nunca se apagan? ¿Es esta la antesala a un nuevo caudal de reinterpretaciones, figuras semióticas e imágenes que surgirán de ese espacio-tiempo aparentemente desterrado de nuestro planeta? Veamos un ejemplo de estas nuevas maneras de "reanimar" los monstruos nocturnos desde una figura muy versátil, y de hecho, una de las figuras contemporáneas más socorridas por el cine, las series de TV, las novelas gráficas y todos sus reclamos de mercadeo como las camisetas, los videojuegos, el porno, el día del orgullo, los desfiles, las fiestas temáticas, apps para convertir una foto en un avatar, los enlaces de serias universidades que exploran su dimensión filosófica ${ }^{13}$, los modelos de simulación para enfrentar una potencial irrupción, etc. Se trata de una potente criatura e ícono ambiguo nacido en las entrañas de la noche: el zombie.

Si bien es posible rastrear la filiación nocturna de esta creatura en la filmografía pionera The Night of the Living Dead (1968) de George A. Romero y en sus secuelas posteriores, esta figura ha sido atractiva culturalmente porque "las historias de zombis funcionan con la misma eficacia que los cuentos infantiles. Los cuentos de hadas eran, en el fondo, historias políticas a través de las cuales era muy fácil poder expresarse [...] No me interesa ser el Michael Moore del horror ni nada por el estilo, pero me siento bien cada vez que soy capaz de

12 En Medellín, los desplazamientos de las actividades de la Calle Colombia a San Juan, a la carrera 70, al Poblado, a las Palmas, etc., hacen bien visible el fenómeno.

13 En el siguiente enlace se pueden consultar algunos análisis filosóficos sobre los zombies https://plato.stanford. edu/entries/zombies/ 
poder expresar y decir las cosas que quiero utilizando este medio" (Serrano, 2009, p. 56). El zombie, así, es una metáfora, ya no necesariamente nocturna aunque venga de esta "cuna", que permite hablar de ámbitos tan diversos como la crítica antimperialista o las omnipotentes y globales corporacione ${ }^{14}$, así como del pacifismo, la ecología, los temores a enfermedades y pandemias, las ideologías intrusivas y manipuladoras, la discriminación, la migración, el desplazamiento y el miedo a lo otro la tecnofobia, etc. De esta manera, permite acuñar esta figura multivalente tan diferente a las de los no-muertos previos como el vampiro, el fantasma, el monstruo hecho con despojos de cadáveres. Esta condición le permite estar cerca, sin confundirse, de otros subgéneros cinematográficos como el cine de catástrofes, el cine de denuncia o el género postapocalíptico como The Cured o The Third Wave (2018). Asimismo, permite enfoques críticos hasta francamente cómicos como Office Uprising (2018), pornográficos como Porn Star Zombies (2009) o L.A. Zombie (2010), musicales, fantásticos o surrealistas como la serie animada Ugly Americans (2009). Incluso borra las fronteras nacionales para adaptarse a contextos bien variados como la película francesa La nuit a devoré le monde (2018) y las tres películas españolas $R E C$ (2007-2012). Por último, también desarrolla secuelas de producciones anteriores como Patient Zero (2018) que retoma la epidemia zombie de 28 Days Later (2002). Todas han sido rodadas desde grandes estudios, estudios independientes o como producciones independientes o underground.

La guetización, gentrificación y apropiación simbólica del espacio urbano abordados por Perrone, Manella y Tripodi (2011) son fenómenos ligados a la especulación inmobiliaria, la exacerbación del control policivo, sus tendencias neoconservadoras y las ingentes olas de turistas. Se expresan en actos de rechazo político y social, como los movimientos antiturísticos, los activismos y reivindicaciones identitarias y territoriales con expresiones que toman forma artística o de protesta antisistema. En el caso de la noche, tales mecanismos de control y limpieza se intensifican, llevando al surgimiento de espacios donde la oscuridad y sus secuelas recobran su protagonismo y atractivo: es el caso del mítico club nocturno berlinés Berghain, paradigma de los muchos que hoy se esparcen alrededor del mundo. Con una entrada bastante controlada y caprichosamente restringida está dirigido paradójicamente a personas de grupos marginalizados y a subculturas urbanas de todos los géneros, fetiches y deseos. A ellos ofrece cuartos oscuros y mazmorras donde la oscuridad reina. No hay reglas y todo puede suceder. ¿Un espacio alternativo u otra forma más sofisticada de comercializar la noche, sus miedos y oscuros deseos? Sea cual sea la respuesta, si la hay, lo que es seguro es que la noche, su oscuridad y sus presencias inquietantes, son desterradas fuera del espacio público. Los

14 La saga Resident Evil es, por ejemplo, un lucha contra una maléfica conspiración corporativa. 
motores de la atracción y afluencia de un público que todavía ve en ellos y en este espacio fabricado para que allí habiten, contrasta con el higienizado mundo urbano de fuera con su noche iluminada y controlada que losexpulsa. Allí se tiene la posibilidad de experimentar la potencia y el carácter indomesticable de la noche, igualmente añorado por bohemios decimonónicos, por goliardos medievales y por urbanitas del siglo XXI que ven allí una forma, particular y cuestionable, de ejercer un activismo antisistema ${ }^{15}$.

Paralelo a ello, el fenómeno de mercantilización de la noche, convertida en "commodity" deseada y a la mano, termina por hacer de esta franja vital un mero escenario vacío, equiparable a un reclamo que llama e incita a su uso y consumo. Evidentemente, las notas de diferenciación son muy obvias: Medellín, ciudad nictófoba y provinciana, apenas está ad-portas de descubrir los potenciales de la noche. Sin embargo, todavía está desgarrada entre el negocio próspero de las tinieblas y su comercialmente conveniente falta de control ${ }^{16}$ y las rancias posiciones morales que ven en la noche aún el peligro y la condenación eterna.

Un mero "experimento" lo constata: una publicación local llamada Ciudad Nocturna. La revista de la noche que se distribuye en hoteles y que declara distribuir 4000 ejemplares, y de la que tengo frente a mí su número 57 del 15 de febrero de 2018, esto es, poco menos de 4 números al año, ofrece, en sus escasas 14 páginas, contenidos que promueven la convivencia:

Bajo la actual administración se ha buscado hacer de la noche un ambiente y un espacio de disfrute propiciado a través de la oferta estética, artística y educativa en donde disfrutar de la noche es un propósito de las políticas, planes y programas de la ciudad. Y donde la resignificación de la 'rumba' debe entenderse como una dimensión constitutiva de la ciudad" (Anónimo, 2018, p. 2).

Esta pretensión de pedagogizar moralmente lo nocturno, de recogerlo bajo el lema "Medellín Convive la noche", de hacerlo "educativo", de domesticarlo, marca el tono del resto de los poco atractivos "artículos" que parecen escritos por la misma persona, y que afirman que la vida nocturna en Medellín "sigue creciendo", que la unión de los comerciantes ha reactivado la noche. También habla del goce derivado de las lunadas, de escuchar un programa radial dedicado a la Sonora Matancera, de una apología del Pueblito paisa, que no se visita de noche habitualmente, de la amenaza tras la trata de "blancas" o de la importancia de la presentación personal (¿en serio?), completado con un artículo sobre New York, el más retórico y sin noche como horizonte y con un extraño "Crusodoku" que completa la edición. Los anuncios: uno de "Gama 3 publicidad", otro de transporte logístico, otro de asesorías contables y otro de apoyo a la juventud

\footnotetext{
15 Con respecto a esto, se recomienda leer el Nightlife as Activism: Brassai, Berghain, and Beyond en el siguiente enlace: http://youthinrevolt4.blogspot.com.co/2015/10/nightlife-as-activism-brassai-berghain.html,

16 Me refiero, claro, a las "otras" economías que florecen mucho más que las legales, aunque casi siempre van de la mano bajo la mesa.
} 
de los barrios con el fútbol. Todos sin relación con lo nocturno mismo. Solo en la contra carátula, una chica anuncia Apteosis [sic] Club, con una dirección, un teléfono y un link a un blog, del que se sospecha sería el único espacio de lo nocturno, donde, contradictoriamente, se practicaría una nocturnidad bien diversa a la del cívico y evangélico propósito de la convivencia ciudadana y la educación. No es el propósito cargar las tintas con un producto tan pobre, pero es el único disponible para cartografiar oficialmente la experiencia de la noche de Medellín y que lo único que devuelve es una imagen recortada y paupérrima de una ciudad que insiste en venderse como ciudad turística.

Si se compara con el número 99 de casi 100 páginas de la guía Madrid en Vivo. La noche en vivo de julio-agosto de 2018, donde se ofrecen espectáculos musicales, de danza, teatro, festivales, galerías de arte, entrevistas con cantantes, playlist de famosos, detallados día a día desde el 1 de julio hasta el 31 de agosto, el contraste no puede ser más evidente entre una noche pacata y domesticada que se ofrece sin brindar nada distinto al visitante a una noche idealizada y sobrepasada por una actividad múltiple pero clandestina no regulada y una sobreoferta que tendría al visitante abrumado durante dos meses con sus días y noches con una variedad cultural abrumadora que no funciona como títere del capricho de un gobierno local sin horizontes o de unos comerciantes sin imaginación. Además de esta, dedicada a las artes escénicas y a la música, hay otras que se especializan en restaurantes, night clubs, oferta a la comunidad LGBT, circuitos alternativos y experimentales de creación, etc. Este ejercicio puede hacerse con ciudades de Latinoamérica más afines a nuestras tradiciones culturales, tarea que no desarrollaré en este artículo, con resultados parecidos.

Es también evidente para un habitante de Medellín, para un turista menos ingenuo de lo que supone la guía mencionada o para nuestros convenientemente ciegos gobernantes. En Medellín sí suceden muchas cosas de noche, esas que la susodicha guía no reconoce o no quiere hacer visibles, sucesos que están por fuera de los eslóganes medrosos de la municipalidad que es la enésima rencarnación del parroquialismo más conservador, el signo contradictorio que alaba al progreso y predica la higiene moral desde el inicio mismo de la modernidad medellinense ${ }^{17}$. Y eso que sucede es espontáneo, diverso, contaminado, ambiguo y cercano, pues al espíritu de la noche, de ese espacio-tiempo ambivalente, aún depara muchas sorpresas para sus viajeros en sus circuitos proliferantes. Este continente es ignoto, pero no inalcanzable, sucede tras bambalinas, en lo que nuestras políticas públicas sobre regulación de la nocturnidad urbana deben abrirse para

17 Este juego de dobles morales no puede menos que evocar a la del viejo franquismo que cierra sus ojos ante los topless playeros de las nórdicas, fuente de ingresos a las maltrechas arcas hispanas bajo el lema del turismo como "industria sin chimeneas", pero sigue al mismo tiempo apegado al guion de su sermón ultraconservador, como maravillosamente lo retrata la serie española Arde Madrid, de Paco León y Anna R. Costa, difundida a fines de 2018 
reconocer sus figuras y dinámicas, asunto sin el cual cojea cualquier medida de entrada por estar cegada por el filtro de falsa ingenuidad, de cerrada moral y de torpe intencionalidad pedagógica ${ }^{18}$. El trabajo del filósofo francés Jacques Rancière (2009) traza una sugestiva ruta: el orden policial vela por un reparto de lo sensible, un acceso a un espacio común de vivencias, signos y experiencias reguladas, como se desprende de nuestras paupérrimas concepciones sobre una noche higienizada e idealizada. A este orden, se enfrenta una actividad política, definida por el esfuerzo de redefinir los contenidos y límites de lo sensible, y que surge siempre como un horizonte inventivo que reta al orden policial. Es en esta dinámica de control y de ampliación donde puede entenderse cómo otras ciudades han abordado su nocturnidad con realismo y creatividad, no con medrosas y convencionales barricadas, siempre desbordadas por la realidad.

\section{Conclusiones}

Ni la conquista contemporánea de la noche por vía del ocio, el consumismo, las tecnologías lumínicas y de vigilancia han logrado erradicar los miedos y figuras metafóricas que la encarnan. Más bien, nuevas formas dan sustento a otras versiones de temores y repulsas, imaginarias o no, que ahora toman el lugar o reviven las ancestrales. Circulan en el soporte globalizado de los medios masivos y asumen, tras apariencias de similitud, valencias bien diversas en cada ciudad contemporánea. Un reconocimiento de tales factores es una condición sine qua non para una gobernanza eficaz de lo nocturno en nuestras ciudades, conectadas globalmente por múltiples medios, tanto tecnológicos como semióticos y de imaginarios sociales.

\section{Agradecimientos}

Este artículo es el resumen de un seminario dictado para la Maestría en Estética de la Universidad Nacional de Colombia, sede Medellín, durante el segundo semestre de 2018.

\section{Referencias}

ABC Madrid. (2014). Las noches de los "juernes" ganan adeptos en Madrid. Recuperado de https://www. abc.es/madrid/20141114/abci-juernes-ganan-adeptos-madrid-201411131745.html

Bogard, P. (2014). El fin de la oscuridad: El ocaso de la noche es una era de luz artificial. Bogotá, Colombia: Planeta.

Bruzzi, S. y Church, P. (Eeds.) (2013). Fashion Cultures Revisited. New York and London: Routledge.

18 Es una historia repetida en sus fracasos, pero, contra toda evidencia, reiterada: el intento de erradicación de la prostitución y su "traslado" a otras zonas urbanas, la penalización de consumos en zonas públicas...entre muchas otras acciones fallidas. 
Carbonell, E. (2004). Debates acerca de la antropología del tiempo. Barcelona: Universitat de Barcelona.

Corbin, A. (1993). El territorio del vacío. Occidente y la invención de la playa (1750-1840). Madrid: Mondadori.

Danesi, M. (2013). On the Metaphorical Connectivity of Cultural. Sign Systems. Signs and Society, 1(1), 33-49. Recuperado de https://www.journals.uchicago.edu/doi/pdfplus/10.1086/670164

Digital Dante Edition (2019) The Divine Comedy by Dante Alighieri. Recuperado de https://digitaldante.columbia.edu/dante/divine-comedy/

El comercio. (2018). Venezuela: Miedo a la delincuencia deja desiertas las noches de Caracas. El Comercio. Recuperado de https://elcomercio.pe/mundo/venezuela/venezuela-miedo-delincuenciadeja-desiertas-noches-caracas-fotos-noticia-nndc-571469

Escorcia, D. (2017). Tiki y taka: Esperando un 'juernes' histórico. El Heraldo. Recuperado de https:// www.elheraldo.co/columnas-de-opinion/tiki-y-taka-esperando-un-juernes-historiCo- 427302

Fideler, D. (2000). Science's Missing Half: Epistemological Pluralism and the Search for an Inclusive Cosmology. Alexandria, Egypt: The Journal of Western Cosmological. Recuperado de http://www. davidfideler.com/files/epistemological-pluralism.pdf

Hard, R. (2004). The Routledge Handbook of Greek Mythology. London: Routledge.

Hesíodo. (1978). Obras y fragmentos: Teogonía, Trabajos y días, Escudo, Fragmentos, Certamen. Madrid: Gredos.

Martin, K. (2011). El libro de los símbolos. Reflexiones sobre las imágenes l viejo, sin comillasarquetípicas. Colonia: Taschen.

Modica, J. (2015). Nightlife as Activism: Brassai, Berghain, and Beyond. Youth In Revolt Fall 2015. Recuperado de http://youthinrevolt4.blogspot.com/2015/10/nightlife-as-activism-brassai berghain.html?view $=$ flipcard

Pastoureau, M. (2017). Los colores de nuestros recuerdos. Cáceres: Periférica.

Perrone, C., Manella, G. y Tripodi, L. (Eds.). (2011). Everyday Life in the Segmented City. U.K.: Emerald Group.

Petrusich, A. (2016). Night Moves. Preserving the Sublime at One of the Darkest Places in America. Virginia Quarterly Review, 92(3). Recuperado de https://www.vqronline.org/essays-articles/2016/07/night-moves

Platón (1872). Obras completas Tomo VI, Madrid: Medina y Navarro Editores.

Plinio el Viejo (2007). Historia Natural. Madrid: Cátedra.

Rancière, J. (2009). El reparto de lo sensible. Estética y política. Santiago de Chile: Arcis - Lom.

Serrano J. (2009). Zombie evolution. El libro de los muertos vivientes en el cine. Madrid: T\&B.

Stoichita, V. (1999). L'Instauration Du Tableau: Métapeinture à L'aube des Temps Moderns. Genève: Droz. 